\title{
Lung Transplantation and the Era of the Sensitized Patient
}

\author{
Katherine A. Young ${ }^{1}$, Hakim A. Ali ${ }^{1}$, Kristi J. Beermann ${ }^{2}$, John M. Reynolds ${ }^{1}$ \\ and Laurie $D$. Snyder ${ }^{1 *}$ \\ 1 Division of Pulmonary, Allergy, and Critical Care Medicine, Department of Medicine, Duke University School of Medicine, \\ Durham, NC, United States, ${ }^{2}$ Department of Pharmacy, Duke University Hospital, Durham, NC, United States
}

Long term outcomes in lung transplant are limited by the development of chronic lung allograft dysfunction (CLAD). Within the past several decades, antibody-mediated rejection (AMR) has been recognized as a risk factor for CLAD. The presence of HLA antibodies in lung transplant candidates, "sensitized patients" may predispose patients to AMR, CLAD, and higher mortality after transplant. This review will discuss issues surrounding the sensitized patient, including mechanisms of sensitization, implications within lung transplant, and management strategies.

\section{OPEN ACCESS}

Edited by:

Jayme E. Locke,

University of Alabama at Birmingham,

United States

Reviewed by:

Rhonda Holdsworth,

Australian Red Cross Blood Service,

Australia

Jakob Nilsson,

University Hospital Zürich, Switzerland

*Correspondence:

Laurie D. Snyder

Laurie.Snyder@duke.edu

Specialty section:

This article was submitted to Alloimmunity and Transplantation,

a section of the journal

Frontiers in Immunology

Received: 31 March 2021

Accepted: 10 May 2021

Published: 26 May 2021

Citation:

Young KA, Ali HA, Beermann KJ,

Reynolds JM and Snyder LD (2021)

Lung Transplantation and the

Era of the Sensitized Patient.

Front. Immunol. 12:689420.

doi: 10.3389/fimmu.2021.689420
Keywords: immunosuppression, allograft dysfunction, antibodies, rejection, lung transplant

\section{INTRODUCTION}

Lung transplantation has become the definitive treatment for many patients with end-stage lung disease. While there have been advances in short term survival, long-term outcomes after lung transplant are limited by the development of chronic lung allograft dysfunction (CLAD) (1). The International Society of Heart and Lung Transplant (ISHLT) defines CLAD as a substantial and persistent decline ( $\geq 20 \%)$ in measured forced expiratory volume in one second (FEV1) value from the reference (baseline) value, which is the mean of the best two postoperative FEV1 measurements (taken $>3$ weeks apart) (2). CLAD can present in a variety of clinical phenotypes. The two most common CLAD phenotypes include an obstructive phenotype called bronchiolitis obliterans syndrome (BOS), defined by a drop in FEV1 but initially preserved functional vital capacity (FVC) and/or preserved total lung capacity (TLC) and a restrictive phenotype called restrictive CLAD/restrictive allograft syndrome (rCLAD/RAS) which is characterized by decline in FVC and/ or TLC in addition to the FEV1 decline (2). Overall, the development of CLAD portends a poor prognosis and contributes to worse survival after transplantation with the median survival being 6.5 years in the most recent era $(3,4)$.

With the poor prognosis of CLAD, lung transplant research has focused on mechanisms, prevention, and treatment of CLAD. One of the strongest and earliest identified risk factors for CLAD is the severity and number of acute cellular rejection episodes (5). Within the past decade, antibody-mediated rejection (AMR) or activation of humoral immunity is being recognized as a separate risk factor for poor long-term outcomes in solid organ transplantation and is considered a risk factor for CLAD in lung transplant recipients specifically $(3,4,6,7)$.

Despite early reports of patients with antibody mediated graft dysfunction, pulmonary AMR lacked a uniform definition making diagnosis and cross-center collaborative studies difficult. Therefore in 2016, ISHLT convened a working group to define pulmonary AMR (8). Alongside developing a definition and classification/grading system for AMR, the group also addressed the 
unique challenges of lung transplant candidates with evidence of detectable antibodies to non-self or "the sensitized" pre-transplant patient (8). This review builds on that initial report and will discuss the implications, challenges, and strategies surrounding the sensitized patient before and after lung transplant.

\section{OVERVIEW OF AMR MECHANISM IN LUNG TRANSPLANT}

In the early 1990s, the phenomenon of antibody-mediated rejection (AMR) was first described in kidney transplant recipients $(9,10)$. In addition to histological changes on graft biopsy, donor-specific antibodies (DSA) were described and closely associated with graft dysfunction. The best characterized donor antibodies are specific to human leukocytes antigens (HLA) and divided into two classes (HLA Class I and II), based on their structure and function (8). Despite the wide ability to detect HLA antibodies after transplant, solid organ transplant communities have defined and responded to AMR quite differently $(4,8)$.

AMR in lung transplant was historically limited to hyperacute rejection, which is thought to occur when preformed DSAs bind to HLA in the donor lung. In these instances, significant and often fatal graft failure occurred within minutes to hours of transplantation and was characterized by hemorrhagic pulmonary edema, severe gas exchange limitation, and diffuse pulmonary infiltrates on imaging studies $(4,11)$. Subsequent identification of HLA antibodies pre-transplant and avoidance of these antigens in the donor has greatly decreased the risk of hyperacute rejection.

AMR related immune activation in the lung includes allospecific B-cells and plasma cells that produce DSAs directed against HLA on the vascular endothelium in the lung allograft. The resulting antigen-antibody complex leads to an amplified immune response or recruitment of immune cells, via both complement-dependent and independent pathways, and subsequent lung tissue pathology and graft dysfunction. Complement is a multifunctional system of receptors, regulators and effector molecules that may amplify both innate and adaptive immunity contributions to $\operatorname{AMR}(4,8,12)$. Notably, pulmonary AMR is different than other solid organ transplant AMR $(4,8)$. For instance, the lung allograft may regulate humoral responses locally (independent of secondary lymphoid organs), as well as peripherally which is contrast to other solid organs which regulate the humoral response peripherally (13).

Preliminary work in pulmonary AMR indicate complementbinding DSA are associated with worse outcomes than non complement-binding DSAs (7). DSA associated complementindependent mechanisms of allograft injury include activation of signaling cascades that leads to endothelial and smooth muscle cell proliferation, release of inflammatory cytokines/chemokines, and platelet activation. These findings suggest DSA may play a role in CLAD $(4,8)$. Of note, lung transplant recipients who develop DSA have a higher risk of developing chronic rejection than individuals who did not develop DSA and worse survival $(3,14)$. One of the strongest risk factors for post-transplant DSA is pre-transplant detectable HLA antibodies, also called allosensitization. In recent years, data from multiple centers confirmed that allosensitization prior to transplant likely increases the risk of $\operatorname{AMR}(14,15)$.

\section{PRE-TRANSPLANT DETECTION OF HLA ANTIBODIES- TECHNIQUES, REPORTING, AND INCIDENCE}

Several studies have demonstrated pre-transplant sensitization with anti-HLA antibodies are associated with decreased waitlist survival and survival after transplantation, increased ventilator days following lung transplant, higher rates of cellular rejection, development of donor-specific HLA antibodies, and bronchiolitis obliterans syndrome (BOS) (3, 16-18), however, this is not a universal finding (19). Various pre-transplant management approaches have been undertaken by the lung transplant community and largely remain institution specific (20). In addition to the potential post-transplant complications, lung transplant candidates with a high-calculated panel reactive antibody (cPRA) often have a longer waitlist time and higher risk of waitlist mortality compared with non-sensitized patients (21). To combat both the pre and post-transplant concerns, centers have employed several therapeutic approaches in an effort to lower or "desensitize" HLA antibody positive individuals prior to transplant (18).

However, many programs will decline highly sensitized lung transplant candidates (21). In a recent survey of lung transplant programs, $21.1 \%$ of programs considered a high cPRA as a contraindication to transplant, while $56.1 \%$ of programs declined offers for listed candidates who are highly sensitized on the basis of HLA antibodies to donor HLA. A minority of programs (14\%) accepted offers regardless of positive virtual crossmatch or actual crossmatch (20). This variability between institutions underscores the need to better understand the effects of allosensitization on transplant related outcomes in an effort to minimize pre and post-transplant morbidity and mortality.

\section{CONSIDERATIONS FOR POLICY CHANGES}

Among the 3,500 transplants performed worldwide annually, approximately $60 \%$ of donors are allocated by the Lung Allocation Score (LAS) or a similar severity of disease score with a focus on maximizing transplant recipient benefit by balancing predicted mortality on the waiting list and one year survival $(22,23)$. While some countries have national wait lists, other countries participate in supranational allocation systems (e.g. Eurotransplant) (22). Although not accounted for in many lung allograft allocation systems, allosensitization is recognized as a barrier to transplant $(21,24)$.

Given the longer waitlist time and thus risk of death on the waiting list, the question has been raised on whether or not allosensitization should be weighted within the LAS or other allocation systems, though this is controversial (25). A singlecenter study found those with any degree of allosensitization were 
less likely to undergo transplant than those without HLA antibodies (17). A separate single-center study considering allosensitization as a continuous variable found allosensitization prolongs the median waiting time and significantly decreases the likelihood of transplant. This study demonstrated a direct relationship between the breadth of allosensitization (as estimated by CPRA) and waiting time, as well as an inverse relationship with the likelihood of lung transplant (21). Given these findings, consideration of allosensitization in organ allocation policies may mitigate the risk of death on the waiting list (21); but with conflicting data regarding whether or not this subset of patients experience higher mortality and complications following transplant (3, 16-19). Thus, it remains difficult to determine whether extra consideration or exceptions for sensitized patients should be made available (26). In 2022, the United States allocation through the Organ Procurement and Transplantation Network will establish a continuous distribution allocation framework and incorporate allosensitization within the new system (27).

\section{PRE-TRANSPLANT SENSITIZATION AND POST-TRANSPLANT OUTCOME}

As noted above, the pre-transplant sensitization is associated with variable post-transplant outcomes. As the most of these are single center, retrospective studies, they should be interpreted with caution (4). On one end of the spectrum, Bosanquet et al. showed that pre-transplant allosensitization does not adversely affect outcomes after lung transplantation such as the development of ACR, lymphocytic bronchiolitis, DSA development, CLAD, graft failure, or mortality when potentially reactive HLA are avoided in the donor by a virtual crossmatch with the recipient (19) and similar findings in CLAD were echoed by Zazueta and colleagues (28). On the other end of the spectrum, several other studies reported significant increases in mortality, acute rejection, BOS, and AMR, as well as increased post-transplant ventilator days $(3,16-18,29)$. Of important note, HLA class II antibodies, especially HLA-DQ antibodies are associated with worse outcomes and may warrant special management considerations $(30,31)$. With the concern that allosensitized lung transplant recipients may have more acute and chronic complications after transplant, it has become a great interest to optimally manage these patients (32).

\section{MANAGEMENT STRATEGIES: WAITLIST AND ALLOCATION CONSIDERATIONS AND THERAPY}

Early referral is one of the most important considerations for highly sensitized patients. Multiple societies recommend early referral to a transplant center for progressive lung disease that has a projected poor prognosis which also allows modifiable barriers to transplant (such as sensitization) to be addressed proactively to optimize candidacy or allow for early listing (33, 34). Often times lung transplant centers face the conundrum of balancing transplant urgency, which can arise as a result of late referral, with pre-transplant immunologic risk. Unfortunately, there is very little literature to guide this decision making process and is often center specific.

For sensitized patients, some centers are using strategies to potentially increase the donor pool with varying success rates. One of the first approaches is to geographically expand the donor pool using a virtual crossmatch. Rather than relying only on a prospective crossmatch for sensitized patients, which is cumbersome as it requires donor cells sent to the recipient center, a virtual crossmatch matching the donor antigens and recipient antibodies was implemented. All recipients still had a laboratory cross match, but after the transplant. Within this group of sensitized patients, the use of virtual crossmatch was associated with decreased number of days on the waitlist and decreased waitlist mortality and replicated the laboratory cross match findings (35).

Many of these management strategies aim to avoid subsequent DSA development in the recipient, as their development has been linked to adverse outcomes $(3,36)$. In one large single center study, DQ mismatching was an independent risk factor for the de novo DSA development (37). Based off this, a management strategy could consider specifically avoiding a DQ mismatch between donor and recipient, but this may not realistic based on the allocation system and recipient medical condition.

Some transplant centers have employed therapeutic approaches in an effort to lower antibodies or "desensitize" individuals prior to transplant or perioperatively $(18,38)$. These targeted desensitization therapies are based on antibody mediated rejection therapies. An early prospective single center study found recipients with post-transplant development of DSA who received either IVIG or combination IVIG/rituximab did not have increased risk for acute cellular rejection, lymphocytic bronchiolitis, BOS or increased mortality (39). With these encouraging results post-transplant results, several programs adopted either a pre-transplant approach or a peri-transplant desentization protocol $(18,38)$.

\section{Pre-Transplant Desensitization Approach in Lung}

Using renal transplant experience, lung transplant centers have tried to desensitize pre-transplant patients (40). Appel et al. retrospectively evaluated efficacy of a peri-transplant desensitization regimen utilizing IVIG and extracorporeal immunoadsorption (ECI) in sensitized lung transplant $(n=34)$ which found a significant reduction in ACR, however no significant difference in development of BOS or mortality following transplant (41).

\section{Peri-Transplant Approach}

A relatively large single center study of 146 patients with known DSA or $c P R A \geq 30 \%$ were treated with a peri-transplant desensitization protocol that included plasmapheresis, IVIG, antithymocyte globulin, and mycophenolic acid. Compared to 194 unsensitized patients, the treated sensitized recipients had significantly lower rates of acute rejection and no significant difference in spirometry, development of CLAD or 1-year graft survival (38). 
In a single center study of highly sensitized patients (cPRA $\geq 80 \%), 18$ pre-transplant patients had an aggressive protocol that included plasmapheresis, methylprednisolone, bortezomib, rituximab, and IVIG. While there was a significant decrease in HLA antibody when measured by MFI, there was no difference in cPRA or mortality (18). Eight of 18 patients completed the protocol and went on to be transplanted.

In a recent single center report, a small group $(n=5)$ of highly sensitized patients (cPRA $\geq 80 \%)$ underwent a peri-transplant multimodal desensitization protocol which included plasmapheresis, rituximab, IVIG, antithymocyte globulin, carfilzomib, and belatacept. With a median follow up time of 427 days, all patients were alive with CLAD-free survival and no episodes of ACR or AMR. Treated patients had a significantly decreased waitlist time compared with historical controls. Of note, several infectious complications were noted (42).

Of recent interest in other solid organ transplants (kidney and heart) is the use of belatacept, a high affinity variant of CTLA4-IG which binds to CD80 and CD86 on antigen presenting cells thereby preventing CD28 mediated signaling critical for T cell activation and proliferation, $\mathrm{T}$ follicular helper cell differentiation, and cognate T/B cell interactions. Belatacept was approved for use in renal transplant recipients on the basis of two randomized controlled trials $(43,44)$. Several centers have reported lower incidence of DSA and superiority in constraining preexisting HLA antibody responses compared with calcineurin inhibitorbased immunosuppression $(45,46)$. When use in combination with desensitization strategies that focus on eliminating antibodies (plasmapheresis) and/or precursor cells responsible for antibody production (proteasome inhibitors and anti-CD20 antibodies) the hope is a more effective, durable "immune modulating" strategy that reliably and sustainably reduces HLA antibodies both before and after transplant (45-47).

Indeed there has been some promising data with the addition of belatacept to desensitization regimens in other solid organ transplant patients (47). Alishetti et al. looked at 4 highly sensitized heart patients (cPRA >99\%) that underwent a multimodal desensitization protocol with a proteasome inhibitor, dexamethasome, and belatacept + /- plasmapheresis prior to heart transplant. In all four patients, desensitization with this regimen decreased the average MFI of class I and II antibodies and in most cases this response was sustained between cycles and after cessation of the proteasome inhibitor. Additionally, the chances of finding a donor to whom the recipient did not have high MFI antibodies increased markedly after desensitization (based on calculated likelihood ratios of cPRA). Of note, two infectious complications were reported which resolved with treatment (47). To date, the small cohort described in lung candidate above is the only known use of CD28 co-stimulation blockade in multimodal lung transplant desensitization protocols and larger scale trials are

\section{REFERENCES}

1. van der Mark SC, Hoek RAS, Hellemons ME. Developments in Lung Transplantation Over the Past Decade. Eur Respir Rev (2020) 29(157):1-16. doi: 10.1183/16000617.0132-2019 needed (42). The higher immunosuppressive effects are attractive in highly allosensitized patients, however safety and efficacy data are yet to be seen (48).

While some centers have reported success in regards to desensitization and transplant related outcomes, the varied protocols, heterogeneous patient populations, and relatively small sample size makes it difficult to draw conclusions regarding the role and impact of desensitization protocols especially in regards to what patients may benefit. Unfortunately, there are not randomized controlled trials that compare the clinical efficacy of different desensitization strategies.

From a logistical standpoint there is a benefit to a pretransplant protocols that can be scheduled as opposed to peritransplant which requires on-demand resources. However, the timing of pre-transplant may hinder the impact of protocols if the transplant occurs considerably later. Additional considerations are the off-label use of therapies which may present substantial cost to the patient or health system and can therefore be a limiting factor to accessing therapies. From a safety standpoint, potential side effects related to certain therapies should be considered in the context of the patient.

\section{DISCUSSION}

Pre-transplant allosensitization remains a considerable barrier in the ability to receive a transplant and avoid complications after transplant. Sensitization limits the number of donors available, thereby extending waitlist time and mortality. Efforts to expand the donor pool often includes intensive therapies that may increase the risk of morbidity and mortality. Even if a suitable donor is found, pre-transplant allosensitization increases the risk for AMR and potentially other complications including CLAD after transplant. Further research is needed in order to best manage the pre and post transplant concerns of allosensitization.

\section{AUTHOR CONTRIBUTIONS}

All authors contributed to the design of the manuscript and editing of the manuscript. Primary writing was done by KY. All authors contributed to the article and approved the submitted version.

\section{ACKNOWLEDGMENTS}

The authors would like to thank the Duke Lung Transplant program patients and staff.

2. Verleden GM, Glanville AR, Lease ED, Fisher AJ, Calabrese F, Corris PA, et al. Chronic Lung Allograft Dysfunction: Definition, Diagnostic Criteria, and Approaches to Treatment-A Consensus Report From the Pulmonary Council of the ISHLT. J Heart Lung Transplant (2019) 38(5):493-503. doi: 10.1016/j.healun.2019.03.009 
3. Snyder LD, Wang Z, Chen DF, Reinsmoen NL, Finlen-Copeland CA, Davis WA, et al. Implications for Human Leukocyte Antigen Antibodies After Lung Transplantation: A 10-Year Experience in 441 Patients. Chest (2013) 144 (1):226-33. doi: 10.1378/chest.12-0587

4. Bery AI, Hachem RR. Antibody-Mediated Rejection After Lung Transplantation. Ann Transl Med (2020) 8(6):401-11. doi: 10.21037/ atm.2019.11.86

5. Parulekar AD, Kao CC. Detection, Classification, and Management of Rejection After Lung Transplantation. J Thorac Dis (2019) 11(Suppl 14): S1732-9. doi: 10.21037/jtd.2019.03.83

6. Lobo LJ, Aris RM, Schmitz J, Neuringer IP. Donor-Specific Antibodies are Associated With Antibody-Mediated Rejection, Acute Cellular Rejection, Bronchiolitis Obliterans Syndrome, and Cystic Fibrosis After Lung Transplantation. J Heart Lung Transplant (2013) 32(1):70-7. doi: 10.1016/ j.healun.2012.10.007

7. Witt CA, Gaut JP, Yusen RD, Byers DE, Luppa JA, Bain KB, et al. Acute Antibody-Mediated Rejection After Lung Transplantation. J Heart Lung Transplant (2013) 32(10):1034-40. doi: 10.1016/j.healun.2013.07.004

8. Levine DJ, Glanville AR, Aboyoun C, Byers DE, Luppa JA, Bain KB, et al. Antibody-Mediated Rejection of the Lung: A Consensus Report of the International Society for Heart and Lung Transplantation. J Heart Lung Transplant (2016) 35(4):397-406. doi: 10.1016/j.healun.2016.01.1223

9. Halloran PF, Schlaut J, Solez K, Srinivasa NS. The Significance of the AntiClass I Response II. Clinical and Pathologic Features of Renal Transplants With Anti-Class I-Like Antibody. Transplantation (1992) 53(3):550-5. doi: 10.1097/00007890-199203000-00011

10. Halloran PF, Wadgymar A, Ritchie S, Falk J, Solez K, Srinivasa NS. The Significance of the Anti-Class I Antibody Response: I. Clinical and Pathologic Features of Anti-Class I-Mediated Rejection. Transplantation (1990) 49 (1):85-91. doi: 10.1097/00007890-199001000-00019

11. Hachem R. Antibody-Mediated Lung Transplant Rejection. Curr Respir Care Rep (2012) 1(3):157-61. doi: 10.1007/s13665-012-0019-8

12. Baldwin WM, Kasper EK, Zachary AA, Wasowska BA, Rodriguez ER. Beyond C4d: Other Complement-Related Diagnostic Approaches to AntibodyMediated Rejection. Am J Transplant (2004) 4(3):311-8. doi: 10.1111/ j.1600-6143.2004.00348.x

13. Li W, Gauthier JM, Higashikubo R, Hsiao HM, Tanaka S, Vuong L, et al. Bronchus-Associated Lymphoid Tissue-Resident Foxp3 + T Lymphocytes Prevent Antibody-Mediated Lung Rejection. J Clin Invest (2019) 129(2):55668. doi: 10.1172/JCI122083

14. Palmer SM, Davis RD, Hadjiliadis D, Hertz MI, Howell DN, Ward FE, et al. Development of an Antibody Specific to Major Histocompatibility Antigens Detectable by Flow Cytometry After Lung Transplant is Associated With Bronchiolitis Obliterans Syndrome. Transplantation (2002) 74(6):799-804. doi: 10.1097/00007890-200209270-00011

15. Hadjiliadis D, Chaparro C, Reinsmoen NL, Gutierrez C, Singer LG, Steele MP, et al. Pre-Transplant Panel Reactive Antibody in Lung Transplant Recipients is Associated With Significantly Worse Post-Transplant Survival in a Multicenter Study. J Heart Lung Transplant (2005) 24(7 SUPPL.):S249-54. doi: 10.1016/j.healun.2004.06.022

16. Shah AS, Nwakanma L, Simpkins C, Williams J, Chang DC, Conte JV. Pretransplant Panel Reactive Antibodies in Human Lung Transplantation: An Analysis of Over 10,000 Patients. Ann Thorac Surg (2008) 85(6):1919-24. doi: 10.1016/j.athoracsur.2008.02.011

17. Kim M, Townsend KR, Wood IG, Boukedes S, Guleria I, Gabardi S, et al. Impact of Pretransplant anti-HLA Antibodies on Outcomes in Lung Transplant Candidates. Am J Respir Crit Care Med (2014) 189(10):1234-9. doi: 10.1164/rccm.201312-2160OC

18. Snyder LD, Gray AL, Reynolds JM, Arepally GM, Bedoya A, Hartwig MG, et al. Antibody Desensitization Therapy in Highly Sensitized Lung Transplant Candidates. Am J Transplant (2014) 14(4):849-56. doi: 10.1111/ ajt.12636

19. Bosanquet JP, Witt CA, Bemiss BC, Byers DE, Yusen RD, Patterson AG, et al. The Impact of Pre-Transplant Allosensitization on Outcomes After Lung Transplantation. J Heart Lung Transplant (2015) 34(11):1415-22. doi: 10.1016/j.healun.2015.06.003

20. Aversa M, Darley DR, Hirji A, Snyder L, Dyu D, Parquin F, et al. Approaches to the Management of Sensitized Lung Transplant Candidates: Findings From an International Survey. J Heart Lung Transplant (2020) 39(4):S215. doi: 10.1016/j.healun.2020.01.709

21. Tague LK, Witt CA, Byers DE, Yusen RD, Aguilar PR, Kulkarni HS, et al. Association Between Allosensitization and Waiting List Outcomes Among Adult Lung Transplant Candidates in the United States. Ann Am Thorac Soc (2019) 16(7):846-52. doi: 10.1513/AnnalsATS.201810-713OC

22. Gottlieb J. Lung Allocation. J Thorac Dis (2017) 9(8):2670-4. doi: 10.21037/ jtd.2017.07.83

23. Egan TM, Murray S, Bustami RT, Shearson TH, McCullough KP, Edwards LB, et al. Development of the New Lung Allocation System in the United States. Am J Transplant (2006) 6(5 II):1212-27. doi: 10.1111/j.1600-6143.2006. 01276.x

24. Tait BD, Süsal C, Gebel HM, Nickerson PW, Zachary AA, Claas FHJ, et al. Consensus Guidelines on the Testing and Clinical Management Issues Associated With HLA and Non-HLA Antibodies in Transplantation. Transplantation (2013) 95(1):19-47. doi: 10.1097/TP.0b013e31827a19cc

25. Aguilar PR, Witt CA, Bemiss BC, Trulock EP, Mohanakumar T, Hachem RR, et al. Desensitization Therapy Before Lung Transplantation. J Heart Lung Transplant (2016) 35(4):S237. doi: 10.1016/j.healun.2016.01.672

26. Ainge-Allen HW, Glanville AR. Timing it Right: The Challenge of Recipient Selection for Lung Transplantation. Ann Transl Med (2020) 8(6):1-11. doi: $10.21037 /$ atm.2019.11.61

27. Alcorn J. Concept Paper- Continuous Distribution of Lungs (2019). OPTN. Available at: https://optn.transplant.hrsa.gov/governance/public-comment/ continuous-distribution-of-lungs-concept-paper/ (Accessed March 27, 2021).

28. Zazueta OE, Preston SE, Moniodis A, Fried S, Kim M, Townsend K, et al. The Presence of Pretransplant HLA Antibodies Does Not Impact the Development of Chronic Lung Allograft Dysfunction or CLAD-Related Death. Transplantation (2017) 101(9):2207-12. doi: 10.1097/TP.0000000000001494

29. Smith JD, Ibrahim MW, Newell H, Danskine AJ, Soresi S, Burke MM, et al. Pre-Transplant Donor HLA-Specific Antibodies: Characteristics Causing Detrimental Effects on Survival After Lung Transplantation. J Heart Lung Transplant (2014) 33(10):1074-82. doi: 10.1016/j.healun.2014.02.033

30. Brugiére O, Suberbielle C, Thabut G, Lhuillier E, Dauriat G, Metivier AC, et al. Lung Transplantation in Patients With Pretransplantation Donor-Specific Antibodies Detected by Luminex Assay. Transplantation (2013) 95(5):761-5. doi: 10.1097/TP.0b013e31827afb0f

31. Aguilar PR, Carpenter D, Ritter J, Yusen RD, Witt CA, Byers DE, et al. The Role of C4d Deposition in the Diagnosis of Antibody-Mediated Rejection After Lung Transplantation. Am J Transplant (2018) 18(4):936-44. doi: 10.1111/ajt.14534

32. Lau CL, Palmer SM, Posther KE, Howell DN, Reinsmoen NL, Massey HT, et al. Influence of Panel-Reactive Antibodies on Posttransplant Outcomes in Lung Transplant Recipients. Ann Thorac Surg (2000) 69(5):1520-4. doi: $10.1016 / \mathrm{S} 0003-4975(00) 01224-8$

33. Shweish O, Dronavalli G. Indications for Lung Transplant Referral and Listing. J Thorac Dis (2019) 11(Suppl 14):S1708-20. doi: 10.21037/ jtd.2019.05.09

34. Ramos KJ, Smith PJ, McKone EF, Pilewski JM, Lucy A, Hempstead SE, et al. Lung Transplant Referral for Individuals With Cystic Fibrosis: Cystic Fibrosis Foundation Consensus Guidelines. J Cyst Fibros (2019) 18(3):321-33. doi: 10.1016/j.jcf.2019.03.002

35. Appel JZ, Hartwig MG, Cantu E, Palmer SM, Reinsmoen NL, Davis RD. Role of Flow Cytometry to Define Unacceptable HLA Antigens in Lung Transplant Recipients With HLA-Specific Antibodies. Transplantation (2006) 81 (7):1049-57. doi: 10.1097/01.tp.0000204046.89396.c5

36. Morrell MR, Pilewski JM, Gries CJ, Pipeling MR, Crespo MM, Ensor CR, et al. De Novo Donor-Specific HLA Antibodies Are Associated With Early and High-Grade Bronchiolitis Obliterans Syndrome and Death After Lung Transplantation. J Heart Lung Transplant (2014) 33(12):1288-94. doi: 10.1016/j.healun.2014.07.018

37. Tikkanen JM, Singer LG, Kim SJ, Li Y, Binnie M, Chaparro C, et al. De Novo DQ Donor-Specific Antibodies are Associated With Chronic Lung Allograft Dysfunction After Lung Transplantation. Am J Respir Crit Care Med (2016) 194(5):596-606. doi: 10.1164/rccm.201509-1857OC

38. Tinckam KJ, Keshavjee S, Chaparro C, Barth D, Azad S, Binnie M, et al. Survival in Sensitized Lung Transplant Recipients With Perioperative Desensitization. Am J Transplant (2015) 15(2):417-26. doi: 10.1111/ajt.13076 
39. Hachem RR, Yusen RD, Meyers BF, Aloush AA, Mohanakumar T, Patterson GA, et al. Anti-Human Leukocyte Antigen Antibodies and Preemptive Antibody-Directed Therapy After Lung Transplantation. J Heart Lung Transplant (2010) 29(9):973-80. doi: 10.1016/j.healun.2010.05.006

40. Vo AA, Lukovsky M, Toyoda M, Wang J, Reinsmoen NL, Lai CH, et al. Rituximab and Intravenous Immune Globulin for Desensitization During Renal Transplantation. N Engl J Med (2008) 359(3):242-51. doi: 10.1056/ nejmoa0707894

41. Appel JZ, Hartwig MG, Davis RD, Reinsmoen NL. Utility of Peritransplant and Rescue Intravenous Immunoglobulin and Extracorporeal Immunoadsorption in Lung Transplant Recipients Sensitized to HLA Antigens. Hum Immunol (2005) 66(4):378-86. doi: 10.1016/j.humimm. 2005.01.025

42. Young KA, Beermann K, Hulbert A, Berry H, Ali H, Reynolds JR. A Novel Post-Transplant Multimodal Antibody Management Protocol for Highly Sensitized Lung Transplant Recipients. J Heart Lung Transplant (2021) 40 (4):S374-5. doi: 10.1016/j.healun.2021.01.1056

43. Durrbach A, Pestana JM, Pearson T, Vincenti F, Garcia VD, Campistol J, et al. A Phase III Study of Belatacept Versus Cyclosporine in Kidney Transplants From Extended Criteria Donors (BENEFIT-EXT Study). Am J Transplant (2010) 10(3):547-57. doi: 10.1111/j.1600-6143.2010.03016.x

44. Vincenti F, Charpentier B, Vanrenterghem Y, Rostaing L, Bresnahan B, Darji $\mathrm{P}$, et al. A Phase III Study of Belatacept-Based Immunosuppression Regimens Versus Cyclosporine in Renal Transplant Recipients (BENEFIT Study). Am J Transplant (2010) 10(3):535-46. doi: 10.1111/j.1600-6143.2009.03005.x

45. Parsons RF, Zahid A, Bumb S, Decker H, Sullivan HC, Lee FE, et al. The Impact of Belatacept on Third-Party HLA Alloantibodies in Highly Sensitized
Kidney Transplant Recipients. Am J Transplant (2020) 20(2):573-81. doi: 10.1111/ajt.15585

46. Bray RA, Gebel HM, Townsend R, Roberts ME, Polinsky M, Yang L, et al. Posttransplant Reduction in Preexisting Donor-Specific Antibody Levels After Belatacept- Versus Cyclosporine-Based Immunosuppression: Post Hoc Analyses of BENEFIT and BENEFIT-EXT. Am J Transplant (2018) 18 (7):1774-82. doi: 10.1111/ajt.14738

47. Alishetti S, Farr M, Jennings D, Serban G, Uriel N, Sayer G, et al. Desensitizing Highly Sensitized Heart Transplant Candidates With the Combination of Belatacept and Proteasome Inhibition. Am J Transplant (2020) 20(12):362030. doi: 10.1111/ajt.16113

48. Parsons RF, Larsen CP, Pearson TC, Badell IR. Belatacept and CD28 Costimulation Blockade: Preventing and Reducing Alloantibodies Over the Long Term. Curr Transplant Rep (2019) 6(4):277-84. doi: 10.1007/s40472019-00260-3

Conflict of Interest: The authors declare that the research was conducted in the absence of any commercial or financial relationships that could be construed as a potential conflict of interest.

Copyright (c) 2021 Young, Ali, Beermann, Reynolds and Snyder. This is an open-access article distributed under the terms of the Creative Commons Attribution License (CC BY). The use, distribution or reproduction in other forums is permitted, provided the original author(s) and the copyright owner(s) are credited and that the original publication in this journal is cited, in accordance with accepted academic practice. No use, distribution or reproduction is permitted which does not comply with these terms. 